\title{
Health-Related Quality of Life in Patients with Multiple Sclerosis: Impact of Disease-Modifying Drugs
}

\author{
Peter Joseph Jongen ${ }^{1,2}$
}

Published online: 12 June 2017

(c) The Author(s) 2017. This article is an open access publication

\begin{abstract}
Multiple sclerosis (MS) has a profound impact on health-related quality of life (HRQoL), a comprehensive subjective measure of the patient's health status. Assessment of HRQoL informs on the potential advantages and disadvantages of disease-modifying drugs (DMDs) beyond their effects on observer-based disability and magnetic resonance imaging abnormalities. This article reviews published data from randomized controlled trials and observational studies regarding the effects of currently available DMDs on HRQoL. Data indicate that DMD treatment is associated with prevention of worsening or with improvement of HRQoL, and that, in general, secondline DMDs may have a greater impact on HRQoL than first-line DMDs. In clinical practice, monitoring of HRQoL provides clinicians with unique information regarding disease impact and potential benefits and adverse effects of DMD treatment that may not be obtained otherwise; it might also permit early detection of an unfavorable disease course. It is suggested to assess HRQoL at the time of diagnosis and before starting or switching DMD treatment. Regular HRQoL measurements contribute to a comprehensive clinical evaluation, and may help to elucidate and quantify the patient's contribution to shared decision making regarding DMD treatment. Further studies are needed to better determine the role of HRQoL assessments in daily MS care.
\end{abstract}

Peter Joseph Jongen

p.j.h.jongen@rug.nl

1 Department of Community and Occupational Medicine, University Medical Center Groningen, Antonius Deusinglaan 1, 9713 AV Groningen, The Netherlands

2 MS4 Research Institute, Ubbergseweg 34, 6522 KJ Nijmegen, The Netherlands

\section{Key Points}

Health-related quality of life (HRQoL) is a patientreported outcome that comprises a comprehensive subjective measure of the patient's health status.

HRQoL provides information on beneficial and adverse treatment effects from the patient's perspective, complementing observer-based outcome measures.

Assessment of HRQoL contributes to an integrated evaluation of the effects of treatment with diseasemodifying drugs (DMDs), predicts disability progression, and helps to formalize patients' input in shared decision making.

Data from randomized controlled trials and observational studies indicate that in relapsingremitting MS, second-line DMDs are generally more strongly associated with prevention of worsening or with improvement of HRQoL than first-line DMDs.

\section{Introduction}

Multiple sclerosis (MS) is a chronic, inflammatory, demyelinating and degenerative disorder of the central nervous system [1]. Although its natural history is highly variable, in the majority of patients MS leads to substantial disability. Approximately $85-90 \%$ of patients present with relapsing-remitting MS (RRMS), which is characterized by recurrent episodes of new or worsening symptoms, followed by at least partial recovery; 
conversion to secondary progressive MS (SPMS) eventually occurs in approximately $75 \%$ of these patients [1]. The remaining $10-15 \%$ present with primary progressive MS (PPMS), which is characterized by progressive disability from disease onset [1]. The number of diseasemodifying drugs (DMDs) available for the treatment of MS has increased considerably in recent years. Interferon (IFN) $\beta-1 \mathrm{a}, \quad$ INF $\beta-1 \mathrm{~b}$, pegylated INF $\beta-1 \mathrm{a}$, glatiramer acetate (GA), natalizumab, fingolimod, dimethyl fumarate (DMF), teriflunomide, alemtuzumab, daclizumab and ocrelizumab are now approved for the treatment of RRMS in many countries $[2,3]$. Ocrelizumab is the only drug approved for PPMS. Mitoxantrone is a general immunosuppressive drug used for the treatment of rapidly worsening RRMS and is currently the only agent approved for the treatment of SPMS [2], although IFN $\beta-1 b$ and subcutaneous IFN $\beta-1 \mathrm{a}$ are approved for the treatment of SPMS with relapses.

Annualized relapse rate (ARR), time to sustained disability progression, and magnetic resonance imaging (MRI) abnormalities are widely used to describe disease activity in MS, and to assess the efficacy of DMDs in clinical trials and the effectiveness of their use in daily practice. A widely applied measure of MS-related disability is the Expanded Disability Status Scale (EDSS) [4]. EDSS scoring is based on neurological examination and ambulation/mobility status [4]; the total score ranges from 0 (normal) to 10 (death from MS) in 0.5-unit increments. This ordinal scale is often criticized for its reliance on walking as the main measure of disability, and its underestimation of fatigue, depression and cognitive symptoms; EDSS scores of $0.0-3.5$ are based on neurological impairments, $4.0-5.5$ on walking distances, $6.0-7.0$ on walking aids, and 7.5 upwards on upper limb function. However, observer-reported outcomes, such as ARR and time to sustained disability progression, do not fully reflect the overall impact of MS on patients [5]. Accordingly, patient-reported outcomes (PROs) are increasingly being used in clinical trials and clinical practice [5]. A PRO is any report of the status of a patient's health condition that comes directly from the patient, without interpretation of the patient's response by a clinician or anyone else [5]. A frequently used PRO is health-related quality of life (HRQoL), which can be defined as the functional effect of an illness and its consequent therapy upon a patient, as perceived by the patient [6]. HRQoL is multidimensional, encompassing physical and occupational function, psychological state, social interaction and somatic sensation [6]. Thus, HRQoL questionnaires aim to provide a broad, comprehensive, subjective measure of disease impact (including health dimensions that cannot be evaluated using observer-based measures) as well as the impact of any (side) effects of treatment [7-10].
Generic HRQoL instruments, such as the Sickness Impact Profile (SIP) [11], the Medical Outcomes Study Short-Form (36-item) Health Survey (SF-36) [12] and the Medical Outcomes Study Short-Form (12-item) Health Survey (SF-12) [13], have been used in MS studies. These tools enable comparison of HRQoL with that in patients with other conditions and the general population. However, important domains unique to MS may be overlooked or underestimated by these instruments. Furthermore, the SF36 has floor and ceiling effects that may limit its usefulness in detecting treatment effects in patients with MS [14].

MS-specific instruments aim to provide a more comprehensive assessment and a greater sensitivity than generic measures (Table 1). The Multiple Sclerosis Quality of Life-54 (MSQoL-54) questionnaire is a hybrid of the SF-36 and 18 additional MS-specific items, generating two summary scores: the physical composite score (PCS) and the mental composite score (MCS) [15]. The Multiple Sclerosis Quality of Life Inventory (MSQLI) is a 138-item hybrid instrument comprising the SF-36 and nine symptom subscales covering fatigue, pain, bowel function, bladder function, emotional status, perceived cognitive function, visual function, sexual satisfaction and social functioning [16]. Both these instruments have been widely used in patients with MS, and the SF-36 portion makes them useful for comparative purposes. In addition to these hybrid questionnaires, a large number of MS-specific HRQoL instruments have been developed, including the Functional Assessment of Multiple Sclerosis (FAMS) [17], the Hamburg Quality of Life Questionnaire in Multiple Sclerosis (HAQUAMS) [18], the Leeds Multiple Sclerosis Quality of Life (LMSQoL) questionnaire [19], the Multiple Sclerosis Impact Scale-29 (MSIS-29) [20] and the Multiple Sclerosis International Quality of Life (MusiQoL) questionnaire [21]. These scales differ considerably in terms of domains covered, complexity, recall period and the time needed to complete them (Table 1). MS-specific instruments that appear less commonly used include the 'RAYS' rating scale [22], the Disability and Impact Profile (DIP) [23], and the Patient-Reported Outcome Indices for Multiple Sclerosis (PRIMUS) [24].

People with MS have a lower HRQoL than the general population [25]. At low disability levels (EDSS $\leq 2.5$ ), differences are clear across all key domains, with an average reduction of $30 \%$ compared with controls of a similar age [25]. Patients with MS generally rate their HRQoL as being lower than patients with other chronic disorders, including epilepsy, diabetes and Parkinson's disease [26, 27]. This likely relates to the fact that in MS a wide range of symptoms may have a negative impact on HRQoL, including anxiety, bowel and/or bladder dysfunction, cognitive impairment, depression, disability, fatigue, pain, sexual dysfunction, sleep quality and 
Table 1 Overview of MS-specific HRQoL questionnaires most commonly used in DMD studies

\begin{tabular}{|c|c|c|c|c|c|}
\hline Instrument & $\begin{array}{l}\text { No. of } \\
\text { items }\end{array}$ & Domains assessed (no. of items) & $\begin{array}{l}\text { Time } \\
\text { period } \\
\text { assessed }\end{array}$ & $\begin{array}{l}\text { Time } \\
\text { taken to } \\
\text { complete }\end{array}$ & Primary outcome measures \\
\hline $\begin{array}{l}\text { MSQoL-54 } \\
{[15]}\end{array}$ & 54 & $\begin{array}{l}\text { Generic (SF-36), energy (1), pain (1), sexual } \\
\text { function/satisfaction (5), cognitive function } \\
\text { (4), health distress/overall QoL (6), social } \\
\text { (1) }\end{array}$ & $\begin{array}{l}\text { Past } 4 \\
\text { weeks }\end{array}$ & $\sim 15 \min$ & $\begin{array}{l}\text { No total score; generates two separate } \\
\text { composite scores for physical and mental } \\
\text { health }(0-100) \text {; higher scores indicate better } \\
\text { QoL }\end{array}$ \\
\hline MSQLI [16] & $\begin{array}{l}138 \\
\left(80^{\mathrm{a}}\right)\end{array}$ & $\begin{array}{l}\text { Generic (SF-36), fatigue (21), pain (6), } \\
\text { sexual function (4), bladder function (4), } \\
\text { bowel function (4), visual function (5), } \\
\text { cognitive function (20), emotional function } \\
\text { (18), social (18) }\end{array}$ & $\begin{array}{l}\text { Past } 4 \\
\text { weeks }\end{array}$ & $\begin{array}{l}45 \min (30 \\
\text { min for } \\
\text { short } \\
\text { form) }\end{array}$ & $\begin{array}{l}\text { No total score; each of the individual } \\
\text { component scales generates a separate } \\
\text { score }\end{array}$ \\
\hline FAMS [17] & 59 & $\begin{array}{l}\text { Symptoms (7), mobility (7), family/social } \\
\text { wellbeing ( } 7) \text {, general contentment (7), } \\
\text { thinking/fatigue (9), emotional wellbeing } \\
\text { (7), additional concerns (15) }\end{array}$ & $\begin{array}{r}\text { Past } 7 \\
\text { days }\end{array}$ & $20-30 \mathrm{~min}$ & $\begin{array}{l}\text { Provides a total score }(0-176) \text { based on } 44 \\
\text { items, with higher scores indicating better } \\
\text { QoL; the additional-concerns subscale } \\
\text { score is not included in the total FAMS } \\
\text { score }\end{array}$ \\
\hline $\begin{array}{l}\text { HAQUAMS } \\
\text { [18] }\end{array}$ & 38 & $\begin{array}{l}\text { Fatigue/thinking (4), mobility of lower limbs } \\
\text { (5), mobility of upper limbs (5), social } \\
\text { function (6), mood (8), sensory symptoms } \\
\text { (2), bladder/bowel control/sexuality (3), } \\
\text { main symptoms (1), recent health changes } \\
\text { (2), disturbed vision (1) and general rating } \\
\text { of handicap (1) }\end{array}$ & $\begin{array}{l}\text { Past } \\
\text { week }^{\mathrm{b}}\end{array}$ & $20 \mathrm{~min}$ & $\begin{array}{l}\text { Provides a total score }(0.00-5.00) \text { based on } \\
\text { five main subdomains; higher scores } \\
\text { indicate poorer QoL; clinically relevant } \\
\text { change defined as }>0.22 \text { change in total } \\
\text { score from baseline [78] }\end{array}$ \\
\hline $\begin{array}{l}\text { LMSQoL } \\
{[19]}\end{array}$ & 8 & $\begin{array}{l}\text { Family/social (2), fatigue/energy ( } 2), \\
\text { psychological status (3), self-confidence/ } \\
\text { appearance (1) }\end{array}$ & $\begin{array}{l}\text { Past } \\
\text { month }\end{array}$ & $\sim 2 \min$ & $\begin{array}{l}\text { Provides a total score }(0-32) \text {; higher scores } \\
\text { indicate better QoL; clinically relevant } \\
\text { improvement defined as } \geq 3 \text {-point increase } \\
\text { from baseline [73] }\end{array}$ \\
\hline $\begin{array}{l}\text { MSIS-29 } \\
{[20]}\end{array}$ & 29 & $\begin{array}{l}\text { Physical impact (20), psychological impact } \\
\text { (9) }\end{array}$ & $\begin{array}{l}\text { Past } \\
2 \text { weeks }\end{array}$ & $5-10 \mathrm{~min}$ & $\begin{array}{l}\text { A combined score can be generated, or both } \\
\text { components can be reported separately } \\
(0-100) \text {; higher scores indicate greater } \\
\text { impact of MS; clinically relevant change } \\
\text { defined as } \geq 7.5 \text { change from baseline for } \\
\text { physical impact score [60] }\end{array}$ \\
\hline $\begin{array}{l}\text { MusiQoL } \\
\text { [21] }\end{array}$ & 31 & $\begin{array}{l}\text { Physical (8), symptoms (4), psychological } \\
\text { (8), self-esteem (4), relationships/friends } \\
\text { (3), relationships/family (4) }\end{array}$ & $\begin{array}{l}\text { Past } \\
4 \text { weeks }\end{array}$ & $\sim 5 \min$ & $\begin{array}{l}\text { Provides a total score }(0-100) \text {; higher scores } \\
\text { indicate better QoL }\end{array}$ \\
\hline
\end{tabular}

$D M D$ disease-modifying drug, FAMS Functional Assessment of Multiple Sclerosis, HAQUAMS Hamburg Quality of Life Questionnaire in Multiple Sclerosis, HRQoL health-related quality of life, LMSQoL Leeds Multiple Sclerosis Quality of Life, MS multiple sclerosis, MSIS-29 Multiple Sclerosis Impact Scale-29, MSQLI Multiple Sclerosis Quality of Life Inventory, MSQoL-54 Multiple Sclerosis Quality of Life-54, MusiQoL Multiple Sclerosis International Quality of Life, QoL quality of life, SF-36 Medical Outcomes Study Short-Form (36-item) Health Survey

a Short form

b All domain items refer to the past week; however, the questionnaire contains two items asking about changes in health status within the past month and the past year

spasticity [28-44]. HRQoL correlates with EDSS score, ARR and MRI abnormalities [45], and low HRQoL has been shown to be an independent predictor of long-term disability [46-48]. The clinical relevance of HRQoL in MS is highlighted by the finding that the effect on quality of life is rated by patients with MS as the second-most important attribute of DMDs [49], and as the third-most important by neurologists and MS nurses [50].

Utility questionnaires have been developed for assessing health outcomes in the context of economic analyses. A widely applied generic utility instrument is the EuroQol 5-Dimensions questionnaire (EQ-5D), which provides a descriptive profile for health status based on five questions regarding mobility, self-care, usual activities, pain/discomfort and anxiety/depression, a single index value and a visual analog scale (VAS) score [51].

Until recently, pivotal trials in MS have tended to lack measures of HRQoL, and its assessment remains underutilized in clinical practice. Regulatory authorities encourage HRQoL assessment in patients with chronic 
illnesses as this can provide additional information from the patient's own perspective regarding the impact of the disease and of therapeutic interventions on symptoms and functions that would not be evaluated using observer-based instruments. In MS, the relevance of HRQoL as an overall subjective measure is underpinned by studies showing that improvement in HRQoL during treatment with DMDs was accompanied by improvements in fatigue, depression or cognition [52-55].

PROs are increasingly being used in randomized controlled trials (RCTs) to establish the (added) value of a drug from the patient perspective. However, as RCTs in MS are designed and powered to detect changes in MRI abnormalities (phase II) or in ARR and time to sustained disability progression (phase III), changes in secondary and tertiary outcomes, such as PROs, may fail to be statistically significant. Moreover, due to their experimental settings and limited time frames, RCTs cannot adequately evaluate the effects of DMD treatment in real life. Observational and controlled effectiveness studies take into account variables relating to real-life conditions, and may therefore better inform about the clinical impact of a treatment.

This paper reviews published data regarding the impact of currently available DMDs on HRQoL in patients with MS, with a focus on implications for clinical practice. To identify studies, a literature search was undertaken in PubMed on 24 April 2017 using the following terms: 'disease modifying' or drug name in title (i.e. interferon, peginterferon, glatiramer, natalizumab, fingolimod, dimethyl fumarate or BG-12, teriflunomide, alemtuzumab, daclizumab, ocrelizumab, mitoxantrone) AND multiple sclerosis AND (quality of life OR health related quality of life OR health impact). Controlled trials or observational studies that provided data on the efficacy of DMDs or the effectiveness of DMD treatment regarding HRQoL were retrieved for review. Further articles were sought via manual searching of retrieved publications. Only articles written in English were considered, and there was no time restriction.

The literature search identified 37 publications that provided sufficient data for inclusion in this review. Data on study characteristics, HRQoL instrument(s) used, baseline values, absolute changes or differences, and statistical significance and clinical relevance of changes or differences were reviewed. Data are presented for each DMD in order of market authorization (except for the IFN $\beta$ products, which are grouped together) and are summarized in Tables 2 and 3. RCTs are presented first, followed by observational studies. The reviewed studies differ considerably in design, duration of follow-up and HRQoL instrument, making it difficult to compare the DMDs. In view of the interpretative difficulties, the various studies are described in detail, so that the readers can make their own judgment. For practical reasons, only dosages and regimens that have obtained market authorization are included. Finally, although statistically significant changes in HRQoL have been reported in numerous DMD studies in MS, the actual mean change from baseline may be numerically small. The minimum clinically important difference (MCID) is the minimum difference that the patient is able to recognize and appreciate [56], and this measure reflects a threshold for an increase to be qualified as improvement. Reported data on HRQoL improvement during treatments are summarized at the end of each DMD section.

\section{Impact of DMDs on Health-Related Quality of Life}

\subsection{Interferon $\beta$}

Five RCTs (three in RRMS and two in SPMS) and nine observational studies in RRMS were identified that provided data on HRQoL during treatment with IFN $\beta$.

Three RCTs assessed the impact of IFN $\beta$ on HRQoL in patients with RRMS [57-59]. In a 2-year, randomized, double-blind, placebo-controlled Multiple Sclerosis Collaborative Research Group study in patients with RRMS, treatment with intramuscular IFN $\beta-1 \mathrm{a}$ resulted in a decrease in mean (standard deviation [SD]) physical SIP score $(-3.78[8.1])$ in patients with baseline SIP scores $\geq 10$, which was greater than that in placebo-treated patients $(p<0.045)$ [57]. The changes in overall $(-4.45$ [8.1]) and psychosocial (-5.86 [12.6]) SIP scores showed a trend towards significance. In a randomized study of 90 patients with newly diagnosed RRMS treated with intramuscular IFN $\beta-1 \mathrm{a}$, subcutaneous IFN $\beta-1 \mathrm{a}$ or IFN $\beta-1 \mathrm{~b}$ for 12 months, mean (SD) MCS of the MSQoL-54 increased from 58.89 (24.31) to 72.93 (28.12) in the IFN $\beta$-1b group ( $p=0.024)$ [58]. In the phase III ADVANCE study, 1512 patients with RRMS were treated with subcutaneous pegylated IFN $\beta-1 \mathrm{a}$ or placebo every 2 or 4 weeks for 48 weeks [59]. Between-group differences in mean change from baseline in physical and psychological MSIS-29 scores were not statistically significant [60].

Two RCTs assessed the impact of IFN $\beta$ on HRQoL in patients with SPMS [61, 62]. In one study, 718 patients were treated with IFN $\beta-1 b$ or placebo for up to 36 months [61]. The SIP total score remained unchanged; however, IFN $\beta-1 b$ was associated with a greater decrease than placebo in the score for the physical component at 6,12 and 36 months, and the psychosocial component at 18 months (all $p \leq 0.05$ ) [61]. In the second study, 436 patients were randomized to treatment with intramuscular IFN $\beta-1 \mathrm{a}$ or placebo for 24 months [62]; changes in 8 of 11 MSLQI 


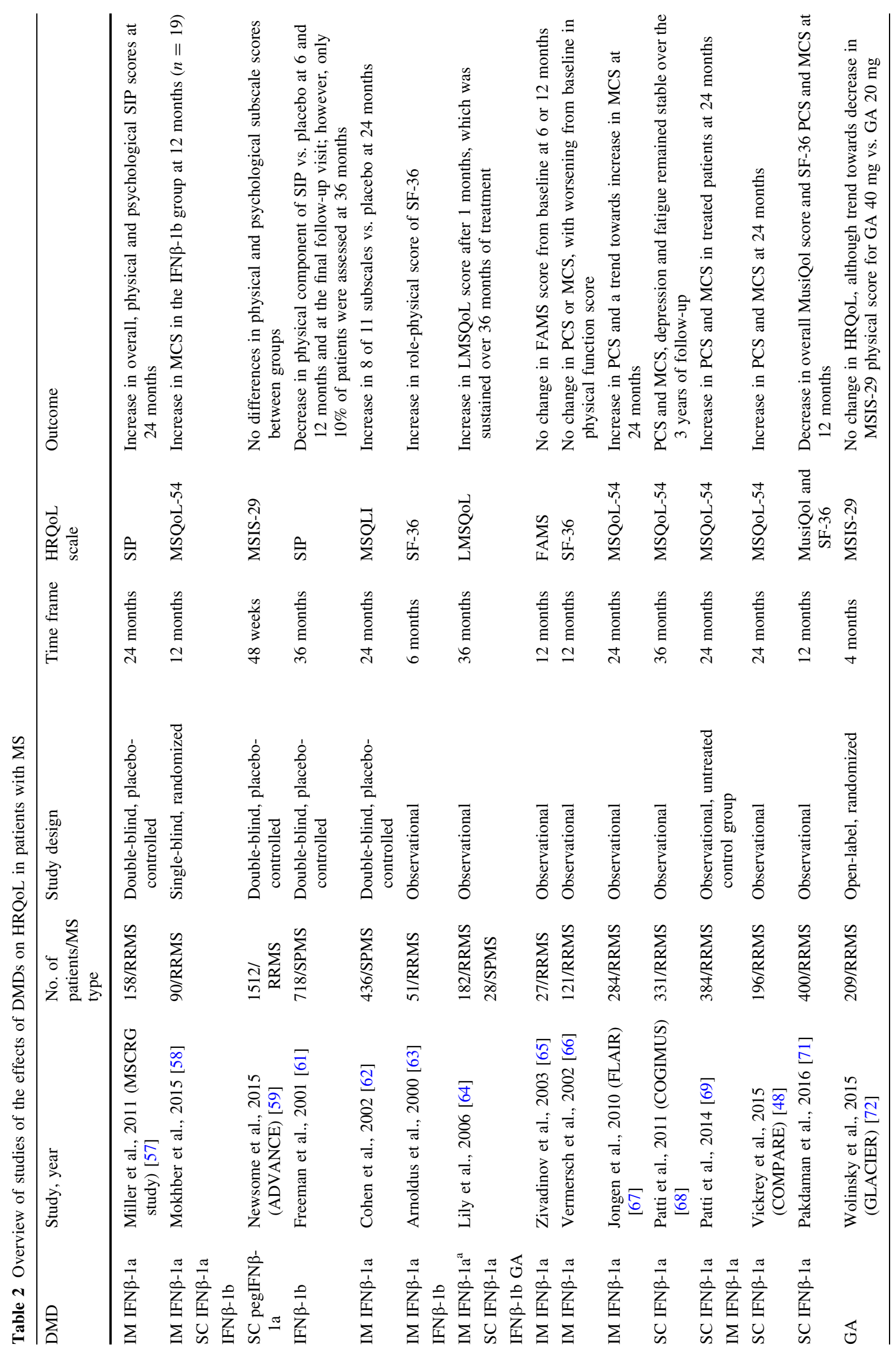




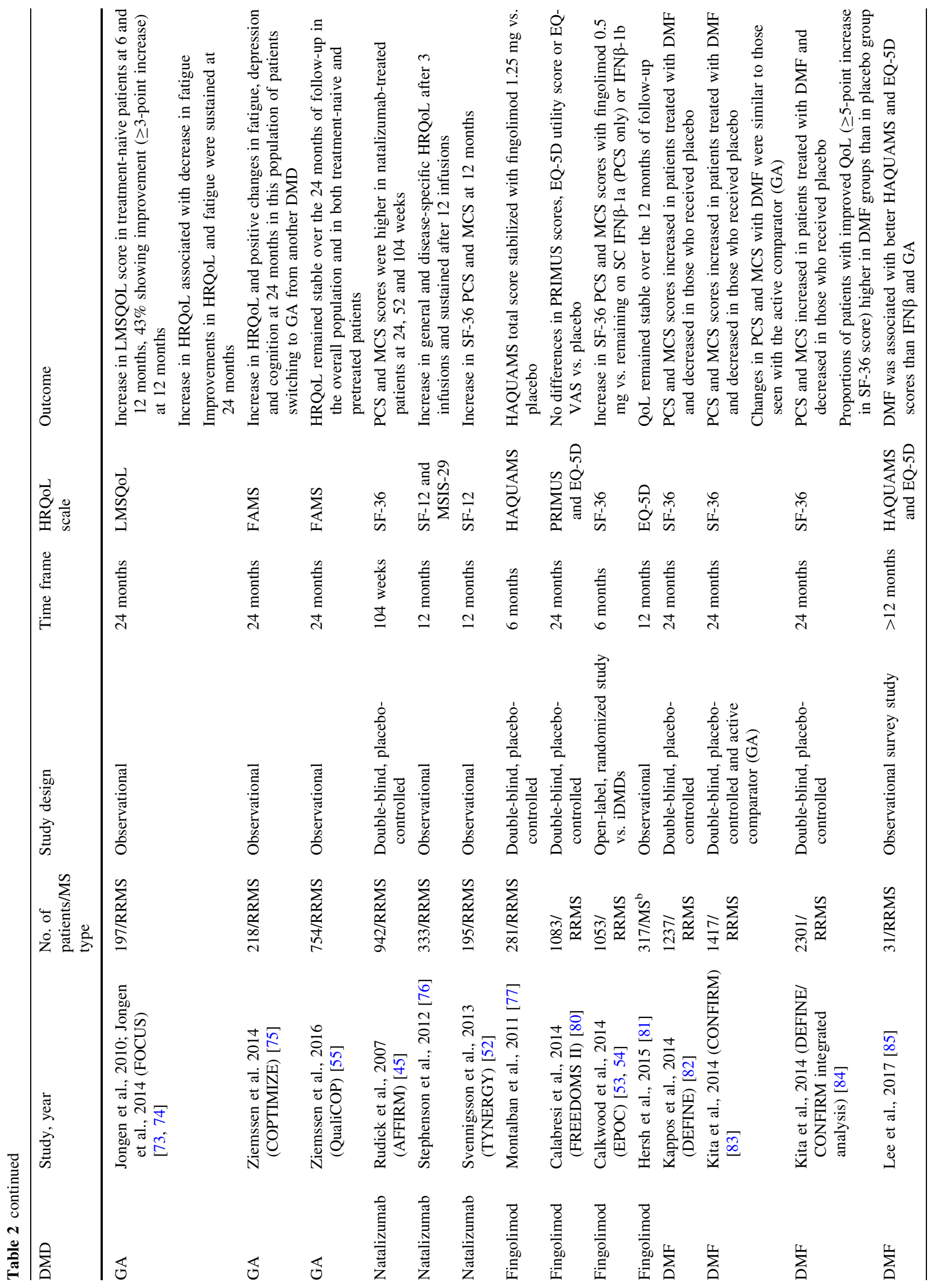




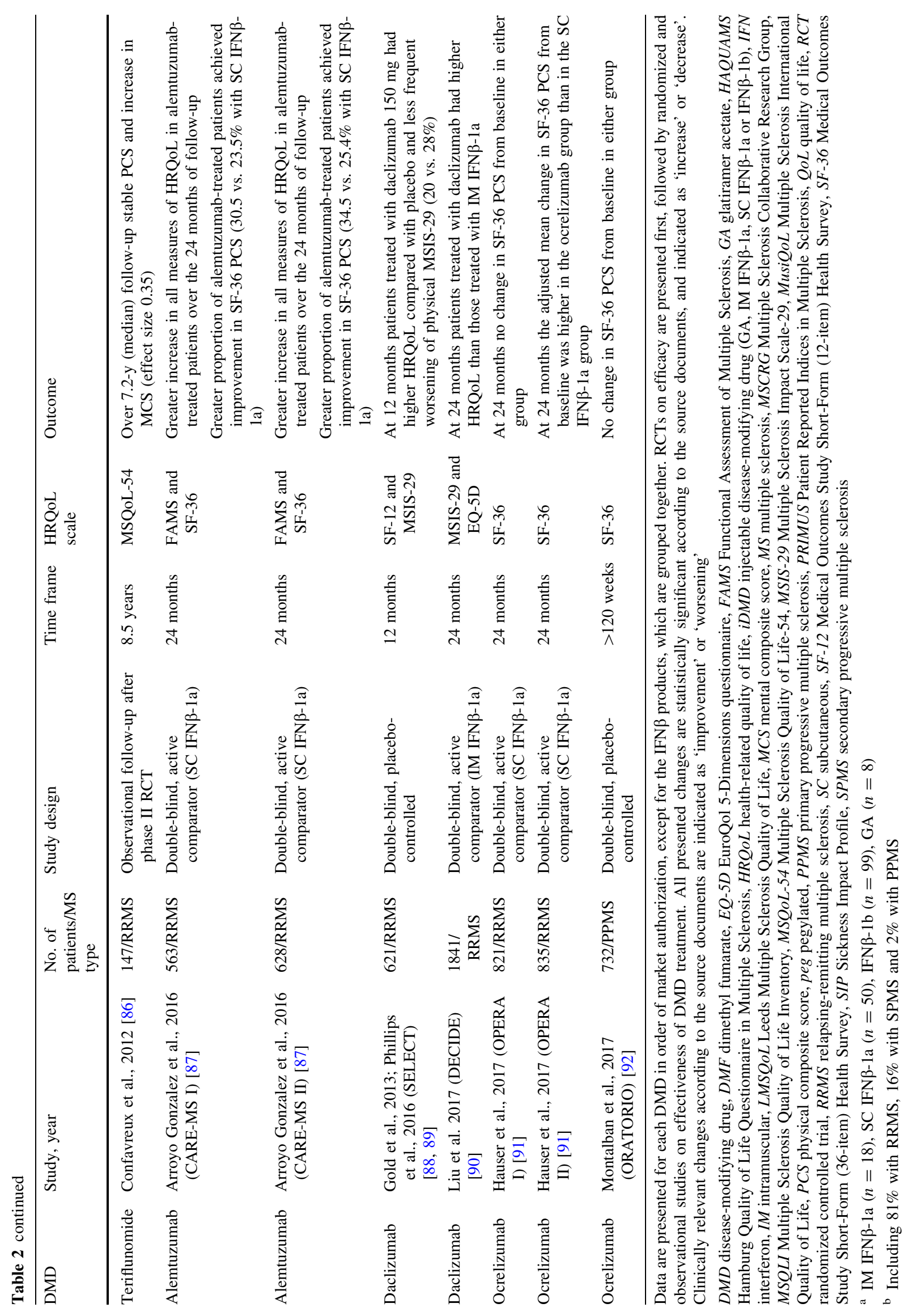




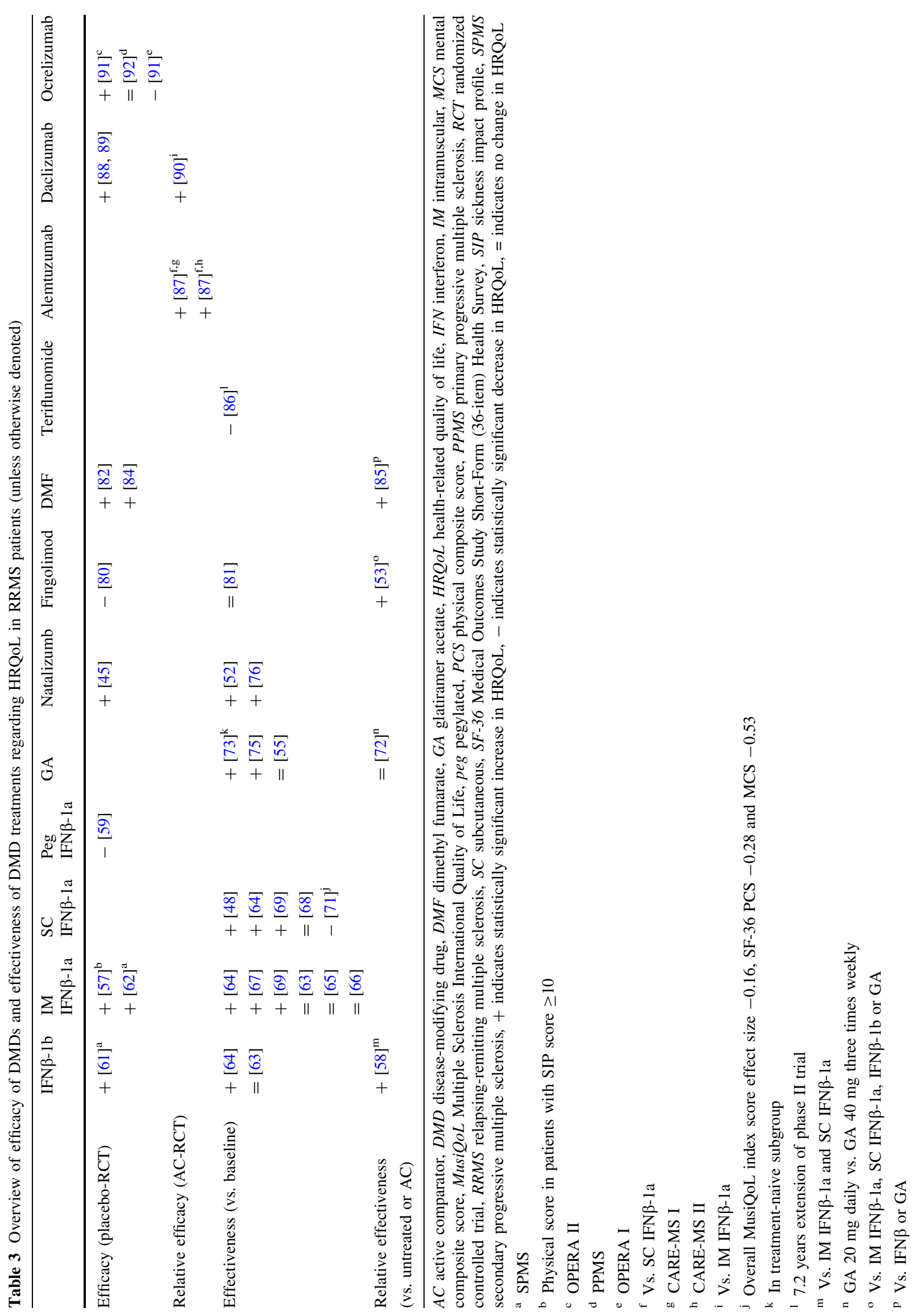


subscales favored intramuscular IFN $\beta-1$ a at 24 months (all $p<0.05)$, including the SF-36 MCS (0.39 [9.1] in the intramuscular INF $\beta$-1a group compared with -1.6 [9.7] in the placebo group).

In an early observational study in 51 RRMS patients treated with intramuscular IFN $\beta$-1a or subcutaneous IFN $\beta$ $1 \mathrm{~b}$ [63], an increase in mean (SD) role-physical functioning subscore of the SF-36 was observed after 6 months, from 33.3 (42.0) to 48.5 (41.9) [ $p=0.032]$, with no changes in PCS, MCS or other subscores. In another observational study in 182 patients with RRMS and 28 patients with SPMS who were treated with intramuscular IFN $\beta-1 \mathrm{a}$ $(n=18)$, subcutaneous IFN $\beta-1 \mathrm{a} \quad(n=50), \quad$ IFN $\beta-1 \mathrm{~b}$ $(n=99)$ or GA $(n=8)$ for up to 3 years [64], an increase in mean LMSQoL score was observed after 1 month $(p=0.0001)$, which was sustained over the follow-up period, with no differences observed between DMDs. In contrast, an observational study of 27 RRMS patients treated with intramuscular IFN $\beta$-1a reported no change in mean FAMS score at 6 or 12 months [65], and another study of 121 patients with RRMS reported no negative impact of intramuscular IFN $\beta-1$ a treatment on SF-36 scores [66].

Recent observational studies have generally shown treatment with IFN $\beta$ to be associated with positive changes in HRQoL in RRMS, most commonly assessed using the MSQoL-54. In a study of neurological practices in The Netherlands, Belgium, UK and Luxembourg, mean (SD) MSQoL-54 PCS increased from 56.6 (16.6) to 61.0 (17.7) $[p<0.05]$ and MCS from 57.2 (16.6) to 61.1 (16.1) $[p=0.07]$ over 2 years of treatment with intramuscular IFN $\beta-1 \mathrm{a}$ in 284 patients with RRMS [67]. In the COGIMUS study conducted in Italy [68], mean MSQoL-54 PCS and MCS remained stable in 331 patients with mild RRMS treated with subcutaneous IFN $\beta$-1a for 3 years (mean [SD] baseline PCS 69.4 [15.8], MCS 66.1 [19.1]). Increases in MSQoL-54 PCS and MCS were reported after 2 years of treatment with intramuscular or subcutaneous IFN $\beta-1 \mathrm{a}$ in another observational study in 394 patients with RRMS in Italy [69]. Mean change in PCS at 2 years was +3.1 and +3.0 in the intramuscular and subcutaneous groups, respectively (mean [SD] baseline scores 67.1 [14.7] and 64.4 [13.9]; both $p<0.05$ ). Respective mean changes in MCS were +4.7 and +5.5 (mean [SD] baseline scores 67.1 [20.6] and 62.5 [21.6]; both $p<0.001$ ). No changes were observed in untreated patients. EDSS progression was associated with HRQoL deterioration.

The COMPARE study was primarily designed to compare the utility and properties of the MusiQol and MSQoL54 in patients with RRMS [70]. In a prespecified secondary analysis of data from 196 patients [48], an increase was observed in mean MSQoL-54 PCS and MCS after 24 months of treatment with subcutaneous IFN $\beta-1 \mathrm{a}$ (approximately 4 points for PCS [ $p=0.027]$ and approximately 6 points for MCS $[p=0.0003]$; mean [SD] baseline scores 60.9 [19.7] and 65.6 [20.5], respectively).

A small (Cohen's $d$ effect size -0.16) mean (SD) decrease of -1.73 (9.15) in MusiQoL score after 1 year's treatment with subcutaneous IFN $\beta$-1a was reported in a recent observational study of 400 patients with RRMS in Iran [71]. A small (Cohen's $d-0.28$ ) decrease in SF-36 PCS ( -5.97 [13.72]) and a moderate (Cohen's $d-0.52)$ decrease in MCS (-9.53 [15.37]) were also noted (mean [SD] baseline scores 78.20 [21.65] and 84.98 [18.06]).

In summary, efficacy of IFN $\beta$ regarding HRQoL was demonstrated in one placebo-controlled RCT in RRMS in a subgroup of patients with low baseline HRQoL [57], and in two placebo-controlled RCTs in patients with SPMS [61, 62]. Five of ten effectiveness studies in RRMS observed an increase in HRQoL during IFN $\beta$ treatment $[48,58,64,67,69]$; improvements were not reported.

\subsection{Glatiramer Acetate}

One open-label RCT and three observational studies reported on HRQoL in patients treated with GA [55, 72-75]. GLACIER was an open-label, randomized, prospective study to assess the safety and tolerability of GA $40 \mathrm{mg}$ three times weekly vs. GA $20 \mathrm{mg}$ daily in patients with clinically stable RRMS who had been treated continuously with GA $20 \mathrm{mg}$ daily for at least 6 months [72]. No changes in physical or psychological well-being were observed, as assessed using the MSIS-29.

In the prospective 12-month observational FOCUS study, changes in HRQoL were assessed during treatment with GA 20 mg daily in 197 patients with RRMS [73, 74]. At 12 months, the mean LMSQoL score was increased in the treatment-naive group $(n=106)$ (mean [SD] change from baseline +2.10 [4.56]; $p<0.001$ ) [73]. In addition, $43 \%$ of treatment-naive patients showed improved HRQoL at 12 months (defined as $\geq 3$-point increase in LMSQoL score). The increase in HRQoL was associated with a reduction in fatigue. An extension of this study found that the changes in HRQoL and fatigue were sustained after 2 years of GA treatment [74]; at this time, the mean LMSQoL change from baseline was 0.76 SD in treatmentnaive patients $(n=29)$ and $0.53 \mathrm{SD}$ in pretreated patients $(n=22)$.

COPTIMIZE was a 2-year prospective study in patients with RRMS who switched to GA $20 \mathrm{mg}$ daily from other DMDs [75], with 218 patients having HRQoL data at baseline and the final examination. At 24 months, the mean FAMS score was increased by +5.95 points $(p=0.0027)$, irrespective of previous treatment or reason for switching. Greater increase was observed in patients who switched to GA because of adverse effects $(+10.81$ points; $p=0.0120)$ 
compared with those who switched due to lack of effectiveness ( +6.62 points; not significant), which would appear to suggest that the resolution of adverse effects contributed to better HRQoL. Positive changes in fatigue, depression and cognition were also reported.

QualiCOP was a 2-year, observational, open-label study in 754 patients with RRMS at 170 sites in Germany [55] prospectively evaluating, in a real-world setting, the longterm effectiveness and tolerability of treatment with GA $20 \mathrm{mg}$ daily. HRQoL assessed by FAMS remained stable over the 2 years of follow-up in the overall population and in both pretreated $(n=273)$ and treatment-naive patients $(n=481)$. However, an increase in cognitive function and decrease in depressive symptoms were reported during the follow-up period (both $p<0.001$ ).

In summary, two observational studies in RRMS found an increase in HRQoL during GA treatment [73-75], and, in one of these, improvement was observed in patients with no previous DMD treatment.

\subsection{Natalizumab}

Three studies on natalizumab treatment and HRQoL were identified, one RCT and two observational studies $[45,52,76]$. AFFIRM was a 2-year phase III trial in which 942 relapsing MS patients were randomized to natalizumab or placebo treatment in a 2:1 ratio [45]. At 104 weeks, mean SF-36 PCS and MCS were higher in natalizumabtreated patients (both $p<0.05$ ) than in those receiving placebo (mean change +0.67 vs. -1.34 for PCS, and +2.00 vs. -0.53 for MCS, respectively; mean baseline PCS was 43.7 in the natalizumab group and 44.3 in the placebo group, and mean baseline MCS was 45.7 and 46.8, respectively). A greater proportion of natalizumab-treated patients than those on the control regimen experienced a clinically relevant increase (improvement) in SF-36 PCS (defined as $\geq 0.5 \mathrm{SD}$ change from baseline to week 104; 24.9 vs. $16.8 \%$, respectively; odds ratio [OR] 1.54). An improvement in SF-36 MCS was observed in 28.5 vs. $21.6 \%$ patients, respectively (OR 1.33).

HRQoL data for natalizumab have also been obtained in clinical practice settings. In an observational study, increases in SF-12 and MSIS-29 scores were observed after 3 months and sustained over 12 months in 333 patients with RRMS treated with natalizumab [76]. Mean change in SF-12 PCS from baseline (34.2) was +2.4 at 12 months $(p<0.0001)$; respective mean change in SF-12 MCS (43.2) was $+3.6(p<0.0001)$. A mean change of -7.1 in MSIS-29 physical impact score from baseline (47.5) was observed at 12 months $(p<0.0001)$, along with a mean change of -7.9 in MSIS-29 psychological impact score (42.0) $[p<0.0001]$. Increases in cognitive functioning and decrease in fatigue were also reported. Moreover, in this study, improvement was defined as an increase of $\geq 5$ points on the SF-12 (range 0-100) and a decrease in at least one category (i.e. $\geq 19$ points) on the MSIS-29. Improved SF-12 PCS and MCS after 12 months were seen in 36 and $39 \%$ of patients, respectively, and improved or stable MSIS-29 physical and psychological impact scores in 43 and $42 \%$, respectively.

In the recent open-label TYNERGY study in $195 \mathrm{MS}$ patients, increases in mean SF-12 PCS and MCS from baseline were reported after 12 months of natalizumab treatment [52]. Mean change was +3.89 for SF-12 PCS and +4.17 for SF-12 MCS $(p<0.0001)$; mean baseline scores were 40.5 and 44.8 .

In summary, one placebo-controlled RCT demonstrated that natalizumab is efficacious in improving physical and mental HRQoL in RRMS [45]. In one of two observational studies, approximately $40 \%$ of patients showed improved physical and mental HRQoL after 12 months of natalizumab treatment [76].

\subsection{Fingolimod}

Three RCTs and one observational study reported on HRQoL during treatment with fingolimod [53, 54, 77, 80, 81].

In a phase II study, 281 RRMS patients were treated for 6 months with placebo or doses of fingolimod that have not been further studied in a phase III trial ( $5 \mathrm{mg}$ daily) or have not been filed for market authorization $(1.25 \mathrm{mg}$ daily) [77]. In this study, clinically relevant HRQoL change (improvement, deterioration) was defined as a change in HAQUAMS total score of $>0.22$ from baseline $[78,79]$. Fewer fingolimod-treated patients $(17.2 \%[1.25 \mathrm{mg}]$ and $19.1 \%$ [5.0 mg]) had a worsened HRQoL at 6 months than placebo-treated patients $(33.0 \%$; both $p<0.05)$; however, the proportions of improved patients did not differ between groups $(18.3 \%[1.25 \mathrm{mg}], 23.6 \%[5.0 \mathrm{mg}]$ and $13.6 \%$ [placebo]).

FREEDOMS II was a 2-year, double-blind, placebocontrolled, phase III study in which 1083 patients with RRMS were randomized to fingolimod $1.25 \mathrm{mg}$, fingolimod $0.5 \mathrm{mg}$ or placebo [80]. HRQoL was a secondary outcome and was assessed using the PRIMUS and EQ-5D questionnaires. No differences were found between the three treatment groups for these outcomes.

In the open-label randomized Evaluate Patient OutComes study [53, 54], 1053 patients with relapsing forms of MS treated with intramuscular IFN $\beta-1 \mathrm{a}$, subcutaneous IFN $\beta-1 \mathrm{a}$, IFN $\beta-1 \mathrm{~b}$ or GA (20 mg daily) were randomized to switch to oral fingolimod $0.5 \mathrm{mg}(n=790)$ or to remain on IFN $\beta$ or GA treatment $(n=263)$. Least-squares mean changes in SF-36 PCS from baseline to 6 months were greater in patients who switched than in those who 
remained on subcutaneous IFN $\beta-1 \mathrm{a} \quad(2.28$ vs. 0.07 ; $p=0.024)$ or IFN $\beta-1 b$ (2.51 vs. $-0.63 ; p=0.022)$, whereas no differences were observed between switching to fingolimod and remaining on GA or intramuscular IFN $\beta$ 1a. An increase in SF-36 MCS was seen after switching compared with remaining on IFN $\beta-1 b$ ( 2.96 vs. -0.50 ; $p=0.03$ ).

In an observational study at an academic medical center in the US, health status assessed using the EQ-5D remained stable in a group of 316 patients (81\% RRMS) for 12 months after fingolimod initiation [81]. Most patients (75\%) switched directly to fingolimod from another DMD.

In summary, in an open-label RCT, the mean change in physical HRQoL in patients switching to fingolimod $0.5 \mathrm{mg}$ was higher than in those remaining on subcutaneous IFN $\beta-1 \mathrm{a}$ or subcutaneous IFN $\beta-1 b$, and the mean change in psychological HRQoL was higher than in those continuing subcutaneous IFN $\beta-1 \mathrm{a}[53,54]$. Health status (EQ-5D) has been reported to remain stable after starting fingolimod treatment [81].

\subsection{Dimethyl Fumarate}

Four studies on DMF and HRQoL were identified: two RCTs, an integrated analysis of these trial results, and a survey study [82-85]. The effect of DMF $240 \mathrm{mg}$ twice daily on HRQoL (SF-36) in patients with RRMS was assessed as a tertiary endpoint in two large, 2-year, doubleblind, placebo-controlled, phase III studies (DEFINE and CONFIRM) [82, 83]. In DEFINE, the 2-year mean change in PCS in the DMF group was +0.45 compared with -1.36 in the placebo group (mean [SD] baseline scores 42.9 [10.02] and 43.3 [10.20], respectively; $p<0.001$ ) [82]. Mean change in MCS was +0.20 and -1.06 in the DMF and placebo groups, respectively (mean [SD] baseline scores 45.3 [10.93] and 45.7 [11.15], respectively; $p<0.002$ ). In addition, improved ( $\geq 5$-point increase) PCS occurred in $24 \%$ of DMF-treated vs. $16.2 \%$ of placebotreated patients (OR 1.8); improved MCS ( $\geq 5$-point increase) was observed in 30.0 and $20.6 \%$, respectively (OR 1.93) [82]. In the CONFIRM study [83], the mean change from baseline in SF-36 PCS at 2 years in the DMF group was higher than in the placebo group or the group receiving GA $20 \mathrm{mg}$ once daily (both $p<0.05$ ). The proportion of patients with improved ( $\geq 5$-point increase) PCS did not differ between fingolimod and placebo, or between GA and placebo.

An integrated analysis of these studies [84] included 769 patients treated with DMF $240 \mathrm{mg}$ twice daily and 771 placebo-treated patients (mean baseline SF-36 PCS and MCS were approximately 43.0 and approximately 45.0, respectively). Overall, $21 \%$ of DMF-treated patients had an improved ( $\geq 5$-point increase) PCS vs. $17.6 \%$ of patients receiving placebo $(p=0.0008)$; an improved MCS was reported in 26.6 and $23.1 \%$ of patients, respectively $(p=0.0221)$.

The effectiveness of DMF treatment regarding HRQoL is suggested by an exploratory analysis of data from a realworld survey among patients with RRMS and their neurologists. Current treatment duration was at least 12 months. In the DMF group $(n=31)$, the estimated average treatment effect for the HAQUAMS total score was -0.45 (95\% CI -0.61 to -0.29$)$ vs. 1.95 (95\% CI $1.86-2.04)$ in patients receiving INF $\beta$ or GA $(n=229$; $p<0.001$ ), and 0.075 (95\% CI $0.014-0.136)$ vs. 0.823 (95\% CI 0.793-0.852) $[p=0.016]$ for the EQ-5D index [85].

In summary, in one RCT in patients with RRMS, DMF was efficacious in improving physical and mental HRQoL compared with placebo [82]. An integrated analysis with data from another RCT confirmed these results [84]. Survey data suggest the effectiveness of DMF treatment in increasing HRQoL compared with INF $\beta-1 \mathrm{a}$ and GA [85].

\subsection{Teriflunomide}

Only limited data are available regarding the effect of teriflunomide on HRQoL. In a phase II long-term extension study in 147 RRMS patients treated with 7 or $14 \mathrm{mg}$ daily [86], patients had a mean reduction of 2.0 on the MSQoL$54 \mathrm{MCS}$ at 7.2 years (effect size 0.11 ) and a mean reduction of 6.1 (effect size 0.35 ) for the PCS. Overall, patients had minimal disability progression (EDSS) over the study period.

\subsection{Alemtuzumab}

Two RCTs provided HRQoL data for alemtuzumab [87]. The two phase III CARE-MS trials with subcutaneous IFN $\beta-1 \mathrm{a} 44 \mu \mathrm{g}$ three times weekly as the comparator [87] included 563 treatment-naive RRMS patients (CARE-MS I) and 628 patients with inadequate response to prior DMD therapy (CARE-MS II). Mean change in FAMS score after 24 months favored alemtuzumab by 4.25 points in CAREMS I $(p<0.05)$ and by 5.34 points in CARE-MS II $(p<0.01)$; mean (SD) baseline scores in the alemtuzumab and IFN $\beta$-1a groups were 133.4 (27.65) and 134.2 (27.61), respectively, in CARE-MS I, and 118.8 (31.64) and 118.8 (32.72), respectively, in CARE-MS II. For SF-36 PCS, between-treatment differences at month 24 favored alemtuzumab in CARE-MS II $(p<0.01)$. The odds of improvement ( $\geq 5$-point increase)/remaining stable vs. worsening on the PCS were greater with alemtuzumab in CARE-MS II (inadequate response to prior DMD therapy) [OR 1.69, $p=0.0111$ ], but not in CARE-MS I (OR 1.39, $p=0.14$ ). For SF-36 MCS, scores at month 24 were 
increased from baseline in both treatment groups in CAREMS I (both $p \leq 0.0009$ ) and CARE-MS II ( $p<0.0001$ for alemtuzumab and $p=0.0478$ for IFN $\beta-1 \mathrm{a}$ ). In both trials, a similar proportion of patients in the two treatment groups had improved SF-36 MCS at 24 months (CARE-MS I: $32.6 \%$ with alemtuzumab vs. $35.2 \%$ with IFN $\beta-1 \mathrm{a}$; CAREMS II: $35.7 \%$ with alemtuzumab vs. $31.6 \%$ with IFN $\beta-1 \mathrm{a}$ ). Finally, the alemtuzumab-treated groups in both studies had increased mean EQ-5D index values and EQ-VAS scores at month $24(p \leq 0.05)$, as did the IFN $\beta$-1a-treated group in the CARE-MS I study $(p \leq 0.05)$. No difference in EQ-5D index or VAS scores at month 24 was seen between treatment groups in CARE-MS I. In contrast, in CARE-MS II, the mean EQ-VAS score at month 24 was higher in the alemtuzumab group $(p<0.05)$.

In summary, in the RCT in RRMS patients with inadequate response to prior therapy (CARE-MS II) [87], alemtuzumab was more efficacious in improving/stabilizing physical HRQoL than subcutaneous IFN $\beta-1 \mathrm{a}$. In an RCT in treatment-naive RRMS patients, alemtuzumab was efficacious in increasing HRQoL compared with subcutaneous IFN $\beta-1$ a.

\subsection{Daclizumab}

Two RCTs were identified that provided HRQoL data for daclizumab [88-90]. Assessment of HRQoL was a tertiary outcome in the placebo-controlled, double-blind SELECT study of the efficacy of subcutaneous daclizumab highyield process $150 \mathrm{mg}$ every 4 weeks and $300 \mathrm{mg}$ every 4 weeks in 621 patients with RRMS [88, 89]. In the $150 \mathrm{mg}$ group (the dose that has been authorized), the mean change in SF-12 PCS and MCS after 52 weeks was +1.2 and +0.7 , respectively (mean [SD] baseline scores 42.9 [9.9] and 46.1 [11.5], respectively) vs. -0.4 and -1.4 , respectively, in the placebo group (mean [SD] baseline scores 42.5 [10.0] and 46.4 [10.2], respectively); these differences were statistically significant (both $p=0.012$ ). Mean changes in MSIS-29 physical and psychological impact scores were -1.0 and -1.8 , respectively, for daclizumab (mean [SD] baseline scores 24.7 [20.2] and 28.6 [21.5], respectively), and +3.0 and +0.6 , respectively, for placebo (mean [SD] baseline scores 26.3 [22.0] and 29.5 [22.5], respectively). The differences between the groups were statistically significant (physical impact score, $p<0.001$ ) or tended towards significance (psychological impact score, $p=0.068$ ). Further analysis of the trial data suggested that an increase of $\geq 7.5$ on the MSIS-29 physical scale could be considered indicative of clinically relevant increase (deterioration) [60]. Using this MCID, the proportion of patients with MSIS-29 physical deterioration at 52 weeks was lower in the daclizumab group than in the placebo group (20 vs. $28 \% ; p<0.01$ ).
DECIDE was a double-blind, phase III trial comparing daclizumab $(n=919)$ with intramuscular IFN $\beta-1$ a $30 \mu \mathrm{g}$ once weekly $(n=922)$ [90]. At week 96 , the odds of patients experiencing a clinically meaningful worsening in MSIS-29 physical score was lower for the daclizumab group (OR 0.76, 95\% CI 0.60-0.95; $p=0.0176$ ); mean (SD) baseline score 21.5 (19.8) for the daclizumab group and 21.9 (19.2) for the intramuscular IFN $\beta$-1a group. Similarly, at week 96 , greater changes occurred in the EQ$5 \mathrm{D}$ index value in the daclizumab-treated group than in the intramuscular IFN $\beta$-1a group $(p=0.005$; baseline 0.74 [0.22] and 0.75 [0.22], respectively), as well as in the EQ-5D VAS score $(2.69$ vs. $0.33 ; p<0.001)$ (baseline 74.1 [19.7] and 73.7 [18.9], respectively).

In summary, in a placebo-controlled RCT in RRMS, daclizumab was efficacious in preventing worsening of physical HRQoL [88, 89]. In another RCT, daclizumab was efficacious in preventing worsening of HRQoL in comparison with intramuscular IFN $\beta-1 a$ [90].

\subsection{Ocrelizumab}

Three RCTs providing data on ocrelizumab and HRQoL were identified [91, 92]. In OPERA I and OPERA II (two identical phase III trials), 821 and 835 patients with RRMS were randomized to intravenous ocrelizumab $600 \mathrm{mg}$ every 24 weeks, or subcutaneous IFN $\beta$ - $1 \mathrm{a} 44 \mu \mathrm{g}$ three times weekly for 96 weeks [91]. In OPERA I, the adjusted mean (95\% CI) change in SF-36 PCS (a secondary endpoint) in the ocrelizumab-treated group was $+0.04(-0.86$ to 0.93 ) and did not differ from that in the subcutaneous IFN $\beta-1 \mathrm{a}$ group $(-0.66[-1.59$ to 0.28$] ; p=0.22)$. In contrast, in OPERA II, the adjusted mean $(95 \% \mathrm{CI})$ change was higher in the ocrelizumab group $(0.33$ [ -0.55 to 1.20$])$ than in the subcutaneous IFN $\beta$-1a group ( -0.83 [ -1.76 to 0.09$]$; $p=0.04)$. In the phase III ORATORIO trial, 732 patients with PPMS were randomized (2:1) to receive intravenous ocrelizumab $600 \mathrm{mg}$ or placebo every 24 weeks for at least 120 weeks [92]. The adjusted mean (95\% CI) change in the secondary endpoint SF-36 PCS did not differ between the groups, being -0.73 (-1.66 to 0.19$)$ in the ocrelizumabtreated group, and $-1.11(-2.39$ to 0.18$)$ in the placebo group $(p=0.60)$. SF-36 MCS values were not reported in these trials.

In summary, in one of two RCTs in RRMS (OPERA II), ocrelizumab was efficacious relative to subcutaneous IFN $\beta-1 \mathrm{a}$ in increasing physical HRQoL [91].

\subsection{Mitoxantrone}

No studies were identified reporting HRQoL data for mitoxantrone. 


\section{Discussion}

In general, the above data show that DMDs may have a positive and beneficial impact on HRQoL in patients with RRMS. For the first-generation DMDs (IFN $\beta-1 b$, intramuscular IFN $\beta-1 \mathrm{a}$, subcutaneous IFN $\beta-1 \mathrm{a}$, and GA $20 \mathrm{mg}$ daily), there is little RCT evidence that these drugs may cause an increase in HRQoL (Table 3); however, most post-authorization studies suggest that real-life use is indeed associated with stabilizing or increasing HRQoL. This discrepancy is most likely due to the fact that when the respective phase III trials were conducted, the scientific community was less aware of the relevance of HRQoL as a desirable additional study outcome. The impact on HRQoL has been more systematically investigated in pivotal RCTs for most of the DMDs authorized since 2004 (natalizumab, fingolimod, DMF, alemtuzumab, daclizumab and ocrelizumab). However, as might be expected, few studies have yet investigated the effectiveness of treatment with the more recently approved DMDs in daily practice regarding HRQoL.

While HRQoL endpoints are increasingly being used in clinical trials, results are not always reported in terms of clinical relevance $[56,93,94]$. A change in score equivalent to 0.5 SD has been found to have almost universal relevance as an MCID for HRQoL [94, 95]. This has been related to psychophysiological evidence that the human limit of cognitive discrimination is approximately one part in seven, which, in many empirical circumstances, is approximately $0.5 \mathrm{SD}[94,95]$. Using the $0.5 \mathrm{SD}$ threshold for the SF-36, a change of $\geq 5$ points in PCS and MCS has been proposed to be clinically meaningful [95]. Applying this MCID in phase III studies, approximately $25-35 \%$ of patients had improved SF-36 PCS and MCS after 2 years of treatment with natalizumab [45], fingolimod [77], DMF [84] and alemtuzumab [87]. Using anchor- and distribution-based methods, the MCID of the MSIS-29 physical impact subscale was found to be $\geq 7.5$ [60], and, with the use of an anchor-based method, an MCID of $\geq 0.22$ was established for the HAQUAMS [78].

To evaluate the clinical relevance of statistically significant changes, we compared the data on improvements in HRQoL for first-line vs. second-line DMDs. Thus, while five of ten effectiveness studies on HRQoL during IFN $\beta$ treatment noted a statistically significant increase [48, 58, 64, 67, 69], none has documented changes that qualified as clinically meaningful. Similarly, while three observational studies found an increase in HRQoL during treatment with GA $20 \mathrm{mg}$ daily [55, 73-75], actual improvements were only observed in one subgroup in one study, namely patients with no previous DMD treatment. As to the impact of second-line DMDs, improvement in
HRQoL has been documented in the phase III placebocontrolled trial, and also in the two observational studies that included HRQoL as a treatment outcome for natalizumab [45, 52, 76]; in one of two RCTs, alemtuzumab was more efficacious in improving or stabilizing physical HRQoL than subcutaneous IFN $\beta-1 \mathrm{a}$ in patients with inadequate response to prior therapy [87]; daclizumab was efficacious in preventing worsening of physical HRQoL in a placebo-controlled RCT, and was more efficacious than intramuscular IFN $\beta-1 \mathrm{a}$ in preventing worsening $\mathrm{HRQOL}$ in another RCT [88-90]. The reviewed data therefore suggest that in RRMS, second-line DMDs generally have a greater impact on HRQoL than the first-line drugs.

There is not necessarily a direct relationship between treatment effectiveness in terms of ARR reduction or delayed disability progression and HRQoL improvement. It may well be that therapeutic changes are partially outweighed by adverse effects. For example, in the SENTINEL study, combination therapy with natalizumab and intramuscular IFN $\beta$-1a was associated with a lower ARR than intramuscular IFN $\beta$-1a alone, and with fewer new or enlarging MRI lesions [45]. However, while a greater proportion of combination-treated patients experienced an improvement in SF-36 PCS (defined as $\geq 0.5$ SD increase), namely 23.3 vs. $17.4 \%$ (OR 1.47), respective proportions of patients with an improved SF-36 MCS were 17.1 vs. 21.0\% (OR 0.99). Notably, some potentially bothersome adverse events occurred more frequently in the combination group, namely anxiety, pharyngitis, sinus congestion and peripheral oedema [45]. The fact that improvements in physician-reported and MRI measures in patients who received combination therapy were not mirrored by an increase in mental HRQoL suggests that, from the patients' perspective, the benefit of less frequent relapses might have been outweighed by adverse events. This interpretation is in line with a report that patients who switched to another DMD because of adverse effects showed a greater increase in HRQoL than those who converted due to lack of effectiveness [75].

Overall, these research data seem to underline the contribution of HRQoL assessment to a more integrated evaluation of DMD treatment in clinical practice. As HRQoL is a comprehensive quantification of the patient's experiences regarding disease and treatment, HRQoL data can contribute to the process of shared decision making, and thus help clinical management decisions, such as whether to initiate, continue or switch DMD treatment. The unique contribution of HRQoL assessment to the evaluation of individual patients is illustrated by the fact that a permanent numbness at a fingertip will hardly have a functional effect in a construction worker, but may severely affect the occupational activities of a professional violinist. 
Recently, it has been reported that the levels of HRQoL and self-efficacy may predict the risk of early treatment discontinuation in patients starting high-frequency GA treatment [96]. When interpreting HRQoL changes over longer periods, response shift may be a concern as subjective self-reported outcomes may be influenced by adaptation to the illness [97], even in patients who are not actively experiencing symptoms on a consistent basis [98].

Given the nature of the underlying concept, the interpretation of HRQoL may pose difficulties in the context of contrary observer-reported data. Discrepancies between changes in EDSS score and HRQoL may be due to DMD adverse effects or to the fact that changes experienced by the patient are not adequately reflected by the EDSS, as outlined above. For example, the occurrence of depressive symptoms during IFN $\beta$ treatment will negatively affect HRQoL, but less so the EDSS score. Similarly, improvement in fatigue during GA treatment is likely to have a greater positive impact on HRQoL than on the EDSS score. The understanding of conflicting or unexpected HRQoL outcomes may be facilitated by the assessment of depression, anxiety, fatigue and cognition, e.g. via the Hospital Anxiety and Depression Scale (HADS), Modified Fatigue Impact Scale (MFIS) and the Symbol Digit Modalities Test, respectively. These symptoms are not only major factors contributing to HRQoL but also are underestimated by the EDSS.

As stated, a large number of HRQoL instruments have been developed for use in patients with MS. In fact, this abundance of instruments may constitute a barrier to their use in clinical practice, with no particular instrument having gained widespread popularity or consensus recommendation. Conceptually, it seems reasonable to assume that MS-specific questionnaires are more appropriate than generic instruments as they focus on disease-specific health problems. The MSQoL-54 and MusiQoL questionnaires are both available in a number of languages, which may facilitate their wider use. In a recent study [70], patients found the shorter MusiQoL easier to use than the MSQoL54 , suggesting that a shorter questionnaire may be more appropriate for use in daily practice. A novel instrument that combines elements of the Center for Epidemiologic Studies Depression Scale, the Medical Outcomes Study Modified Social Support Survey, the MFIS, and the MSQoL-54 is under investigation [99].

In general, lack of time and resources are major constraints on the standard use of HRQoL questionnaires in clinical practice [7]. To some extent, this may be overcome by making questionnaires available online so that they can be completed at home or at the clinic before the consultation. Furthermore, with online assessments, errors and missing data are minimized by automated checks of completeness and consistency, and scores are calculated automatically and can be displayed graphically. A shorter electronic version of the MSQoL-54 with automatic scoring (the MSQoL-29, which preserves key HRQoL dimensions) is currently being validated [100]. A multidimensional computerized adaptive short-form version of the MusiQoL is also under development [101].

Online monitoring by use of PROs appears feasible in patients with MS. In a study that investigated whether patients with RRMS would adhere to the monthly online completion of two short questionnaires to monitor the effectiveness of DMD treatment, $75 \%$ of patients performed all assessments during the 12 months of follow-up [102]. Sending SMS or email reminders may further increase compliance. However, embedding PRO monitoring into daily care processes and consistent utilization of outcomes by healthcare professionals during their consultations seems even more important. Thus, two HRQoL questionnaires (MSQoL-54, LMSQoL) form part of MSmonitor, an interactive web-based program for selfmanagement and integrated multidisciplinary care in patients with MS [103, 104]. This program, which also includes, among others, the HADS and MFIS-5, is being used successfully in The Netherlands.

Based on the above, a set of guidelines may be suggested for the assessment of HRQoL in daily MS care. Ideally, the questionnaire used should be one for which the MCID has been established, that is available for online completion, and that is embedded in a web-based program including depression, anxiety, fatigue and cognition scales. Baseline HRQoL should be assessed at the time of diagnosis, before starting or switching DMD treatment, and possibly also to help identify patients at high risk of early treatment discontinuation. Monitoring of HRQoL via assessments at regular intervals enables the detection of improvements and deteriorations, the latter being warning signs for an increase in disability. HRQoL outcomes need to be interpreted in relation to symptoms and adverse treatment effects, and discussed with patients during consultations. They contribute to an integrated evaluation of disease course and/or treatment effects, and may be used in the process of shared decision making.

These proposed measures may be thought of as complex interventions that have to be investigated for their feasibility, effectiveness and cost effectiveness, e.g. via mixedmethods methodology and RCTs. Other topics that may be subjects for future research are the establishment of MCIDs for all available HRQoL instruments; the further development of short, specific or adaptive questionnaires; the further assessment of the predictive value of HRQoL worsening regarding disability progression; and the contribution of HRQoL to risk stratification with respect to early DMD discontinuation. Interestingly, it has been argued recently that the MCID for a particular PRO 
instrument is not an immutable characteristic, but may vary by population and context, including the clinical context, decision at hand, the baseline from which the patient starts, and whether he or she is improving or deteriorating [94]. For such a personalized application of HRQoL to become reality, it seems necessary, among others, to obtain national or regional reference values. Data from patient registries, such as the North American Research Committee on Multiple Sclerosis (NARCOMS), Patients Like Me, and the Swedish MS Registry [105-107], and from longitudinal, web-based, patient-centred studies [108] may provide such information about HRQoL over the disease course and the impact of DMDs. For example, recent data for almost 4000 patients from the NARCOMS registry suggest that preventing, or at least minimizing, HRQoL decline in the early stages of the disease may be the best way to ensure high levels of HRQoL over time [107].

\section{Conclusion}

HRQoL quantifies subjective aspects of the patient's health status. Data from RCTs and observational studies in RRMS indicate that DMD treatment is associated with prevention of worsening or with improvement of HRQoL. Despite differences in design, duration of follow-up and HRQoL instrument, studies suggest that, in general, second-line DMDs may have a greater impact on HRQoL than first-line DMDs. In clinical practice, monitoring of HRQoL provides clinicians with unique information regarding disease impact and the potential benefits and adverse effects of DMD treatment that may not be obtained otherwise, and might also permit early detection of an unfavorable disease course. HRQoL assessment may help to elucidate and quantify the patient's contribution to shared decision making regarding DMD treatment. Further studies are needed to better determine the role of HRQoL assessments in daily MS care.

Acknowledgements I am grateful to Jennifer Coward of Anthemis Consulting Ltd who, under my guidance, undertook the literature search, assisted in the selection of studies for inclusion and provided medical writing support at all stages of manuscript development. TEVA Pharmaceuticals, Frazer, PA, USA, funded Jennifer Coward's activities and provided a medical-accuracy review of the manuscript.

\section{Compliance with Ethical Standards}

Funding I did not receive funding for the preparation of this review. Open access was funded by the University of Groningen, Groningen, as part of the Compact agreement between Springer and the Association of Dutch Universities and Academy Institutes.

Conflict of interest I have received honoraria from Bayer, Merck, Mylan and TEVA for consultancy activities.
Open Access This article is distributed under the terms of the Creative Commons Attribution-NonCommercial 4.0 International License (http://creativecommons.org/licenses/by-nc/4.0/), which permits any noncommercial use, distribution, and reproduction in any medium, provided you give appropriate credit to the original author(s) and the source, provide a link to the Creative Commons license, and indicate if changes were made.

\section{References}

1. Kamm CP, Uitdehaag BM, Polman CH. Multiple sclerosis: current knowledge and future outlook. Eur Neurol. 2014;72:132-41.

2. Wingerchuk DM, Carter JL. Multiple sclerosis: current and emerging disease-modifying therapies and treatment strategies. Mayo Clin Proc. 2014;89:225-40.

3. Vargas DL, Tyor WR. Update on disease-modifying therapies for multiple sclerosis. J Investig Med. 2017. doi:10.1136/jim2016-000339.

4. Kurtzke JF. Rating neurologic impairment in multiple sclerosis: an expanded disability status scale. Neurology. 1983;33(11):1444-52.

5. Food and Drug Administration. Guidance for Industry. Patientreported outcome measures: use in medical product development to support labeling claims; 2009. http://www.fda.gov/ downloads/Drugs/GuidanceComplianceRegulatoryInformation/ Guidances/UCM193282.pdf. Accessed 10 May 2017.

6. Schipper H, Clinch JJ, Olweny CLM. Quality of life studies: definitions and conceptual issues. In: Spilker B, editor. Quality of life and pharmacoeconomics in clinical trials. Philadelphia: Lippincott-Raven; 1996. p. 11-24.

7. Solari A. Role of health-related quality of life measures in the routine care of people with multiple sclerosis. Health Qual Life Outcomes. 2005;3:16.

8. Rudick RA, Miller DM. Health-related quality of life in multiple sclerosis: current evidence, measurement and effects of disease severity and treatment. CNS Drugs. 2008;22:827-39.

9. Zwibel HL, Smrtka J. Improving quality of life in multiple sclerosis: an unmet need. Am J Manag Care. 2011;17(Suppl 5):S139-45.

10. Baumstarck K, Boyer L, Boucekine M, Michel P, Pelletier J, Auquier P. Measuring the quality of life in patients with multiple sclerosis in clinical practice: a necessary challenge. Mult Scler Int. 2013;2013:524894.

11. Bergner M, Bobbitt RA, Carter WB, Gilson BS. The Sickness Impact Profile: development and final revision of a health status measure. Med Care. 1981;19:787-805.

12. Ware JE Jr, Sherbourne CD. The MOS 36-item short-form health survey (SF-36). I. Conceptual framework and item selection. Med Care. 1992;30:473-83.

13. Ware J Jr, Kosinski M, Keller SD. A 12-Item Short-Form Health Survey: construction of scales and preliminary tests of reliability and validity. Med Care. 1996;34:220-33.

14. Hobart J, Freeman J, Lamping D, Fitzpatrick R, Thompson A. The SF-36 in multiple sclerosis: why basic assumptions must be tested. J Neurol Neurosurg Psychiatry. 2001;71:363-70.

15. Vickrey BG, Hays RD, Harooni R, Myers LW, Ellison GW. A health-related quality of life measure for multiple sclerosis. Qual Life Res. 1995;4:187-206.

16. Ritvo PG, Fischer JS, Miller DM, Andrews H, Paty DW, LaRocca NG. Multiple Sclerosis Quality of Life Inventory (MSQLI): a user's Manual. National Multiple Sclerosis Society; 1997. http://walkcoc.nationalmssociety.org/docs/HOM/MSQLI_ Manual_and_Forms.pdf. Accessed 10 May 2017. 
17. Cella DF, Dineen K, Arnason B, et al. Validation of the functional assessment of multiple sclerosis quality of life instrument. Neurology. 1996;47:129-39.

18. Gold SM, Heesen C, Schulz H, et al. Disease specific quality of life instruments in multiple sclerosis: validation of the Hamburg Quality of Life Questionnaire in Multiple Sclerosis (HAQUAMS). Mult Scler. 2001;7:119-30.

19. Ford HL, Gerry E, Tennant A, Whalley D, Haigh R, Johnson $\mathrm{MH}$. Developing a disease-specific quality of life measure for people with multiple sclerosis. Clin Rehabil. 2001;15:247-58.

20. Hobart J, Lamping D, Fitzpatrick R, Riazi A, Thompson A. The Multiple Sclerosis Impact Scale (MSIS-29): a new patient-based outcome measure. Brain. 2001;124:962-73.

21. Simeoni M, Auquier P, Fernandez O, et al. Validation of the Multiple Sclerosis International Quality of Life questionnaire. Mult Scler. 2008;14:219-30.

22. Rotstein Z, Barak Y, Noy S, Achiron A. Quality of life in multiple sclerosis: development and validation of the 'RAYS' scale and comparison with the SF-36. Int J Qual Health Care. 2000;12:511-7.

23. Lankhorst GJ, Jelles F, Smits RC, et al. Quality of life in multiple sclerosis: the disability and impact profile (DIP). J Neurol. 1996;243:469-74.

24. Doward LC, McKenna SP, Meads DM, Twiss J, Eckert BJ. The development of patient-reported outcome indices for multiple sclerosis (PRIMUS). Mult Scler. 2009;15:1092-102.

25. The Canadian Burden of Illness Study Group. Burden of illness of multiple sclerosis. Part II: quality of life. Can J Neurol Sci. 1998;25:31-8.

26. Hermann BP, Vickrey B, Hays RD, et al. A comparison of health-related quality of life in patients with epilepsy, diabetes and multiple sclerosis. Epilepsy Res. 1996;25:113-8.

27. Riazi A, Hobart JC, Lamping DL, et al. Using the SF-36 measure to compare the health impact of multiple sclerosis and Parkinson's disease with normal population health profiles. J Neurol Neurosurg Psychiatry. 2003;74:710-4.

28. Amato MP, Ponziani G, Rossi F, Liedl CL, Stefanile C, Rossi L. Quality of life in multiple sclerosis: the impact of depression, fatigue and disability. Mult Scler. 2001;7:340-4.

29. Benito-León J, Morales JM, Rivera-Navarro J. Health-related quality of life and its relationship to cognitive and emotional functioning in multiple sclerosis patients. Eur $\mathrm{J}$ Neurol. 2002;9:497-502.

30. Lobentanz IS, Asenbaum S, Vass K, et al. Factors influencing quality of life in multiple sclerosis patients: disability, depressive mood, fatigue and sleep quality. Acta Neurol Scand. 2004;110:6-13.

31. Pittion-Vouyovitch S, Debouverie M, Guillemin F, Vandenberghe N, Anxionnat R, Vespignani H. Fatigue in multiple sclerosis is related to disability, depression and quality of life. J Neurol Sci. 2006;243:39-45.

32. Nogueira LA, Nóbrega FR, Lopes KN, Thuler LC, Alvarenga RM. The effect of functional limitations and fatigue on the quality of life in people with multiple sclerosis. Arq Neuropsiquiatr. 2009;67:812-7.

33. Flensner G, Landtblom AM, Söderhamn O, Ek AC. Work capacity and health-related quality of life among individuals with multiple sclerosis reduced by fatigue: a cross-sectional study. BMC Public Health. 2013;13:224.

34. Chruzander C, Ytterberg C, Gottberg K, Einarsson U, Widén Holmqvist L, Johansson S. A 10-year follow-up of a populationbased study of people with multiple sclerosis in Stockholm, Sweden: changes in health-related quality of life and the value of different factors in predicting health-related quality of life. J Neurol Sci. 2014;339:57-63.
35. Kohn CG, Baker WL, Sidovar MF, Coleman CI. Walking speed and health-related quality of life in multiple sclerosis. Patient. 2014;7:55-61.

36. Schairer LC, Foley FW, Zemon V, et al. The impact of sexual dysfunction on health-related quality of life in people with multiple sclerosis. Mult Scler. 2014;20:610-6.

37. Vitkova M, Rosenberger J, Krokavcova M, et al. Health-related quality of life in multiple sclerosis patients with bladder, bowel and sexual dysfunction. Disabil Rehabil. 2014;36:987-92.

38. Lysandropoulos AP, Havrdova E, ParadigMS Group. 'Hidden' factors influencing quality of life in patients with multiple sclerosis. Eur J Neurol. 2015;22(Suppl 2):8-33.

39. Tabrizi FM, Radfar M. Fatigue, sleep quality, and disability in relation to quality of life in multiple sclerosis. Int J MS Care. 2015;17:268-74.

40. Berrigan LI, Fisk JD, Patten SB, et al. Health-related quality of life in multiple sclerosis: direct and indirect effects of comorbidity. Neurology. 2016. doi:10.1212/WNL.0000000000002564.

41. Hayter AL, Salkovskis PM, Silber E, Morris RG. The impact of health anxiety in patients with relapsing remitting multiple sclerosis: misperception, misattribution and quality of life. Br J Clin Psychol. 2016;55:371-86.

42. Khalaf KM, Coyne KS, Globe DR, et al. The impact of lower urinary tract symptoms on health-related quality of life among patients with multiple sclerosis. Neurourol Urodyn. 2016;35:48-54.

43. Milinis K, Tennant A, Young CA, TONiC Study Group. Spasticity in multiple sclerosis: associations with impairments and overall quality of life. Mult Scler Relat Disord. 2016;5:34-9.

44. Wilski M, Tasiemski T. Health-related quality of life in multiple sclerosis: role of cognitive appraisals of self, illness and treatment. Qual Life Res. 2016;25:1761-70.

45. Rudick RA, Miller D, Hass S, et al. Health-related quality of life in multiple sclerosis: effects of natalizumab. Ann Neurol. 2007;62:335-46.

46. Baumstarck K, Pelletier J, Butzkueven H, et al. Health-related quality of life as an independent predictor of long-term disability for patients with relapsing-remitting multiple sclerosis. Eur J Neurol. 2013;20(907-914):e78-9.

47. Kisic Tepavcevic D, Pekmezovic T, Stojsavljevic N, et al. Predictive value of health-related quality of life in progression of disability and depression in persons with multiple sclerosis: a 3-year study. Acta Neurol Belg. 2013;113:403-9.

48. Vickrey BG, Lee L, Moore F, Moriarty P. EDSS change relates to physical HRQoL while relapse occurrence relates to overall HRQoL in patients with multiple sclerosis receiving subcutaneous interferon $\beta-1 \mathrm{a}$. Mult Scler Int. 2015;2015:631989.

49. Kremer IE, Evers SM, Jongen PJ, van der Weijden T, van der Kolk I, Hiligsmann M. Identification and prioritization of important attributes of disease-modifying drugs in decision making among patients with multiple sclerosis: a nominal group technique and best-worst scaling. PLoS One. 2016;11:e0164862.

50. Kremer IE, Evers SM, Jongen PJ, van der Weijden T, Hiligsmann M. A comparison of neurologists' and MS nurses' with MS patients' preferences for the characteristics of disease modifying drugs for decision making. European Committee for Treatment and Research in Multiple Sclerosis 2016, P1442. http://onlinelibrary. ectrims-congress.eu/ectrims/2016/32nd/145826/peter.jongen.a. comparison.of.neurologists.and.ms.nurses.with.ms.patients.html? $\mathrm{f}=\mathrm{m} 1$. Accessed 10 May 2017.

51. EuroQol Group. EuroQol-a new facility for the measurement of health-related quality of life. Health Policy. 1990;16:199-208.

52. Svenningsson A, Falk E, Celius EG, et al. Natalizumab treatment reduces fatigue in multiple sclerosis. Results from the 
TYNERGY trial: a study in the real life setting. PLoS One. 2013;8:e5864391.

53. Calkwood J, Cree B, Crayton H, et al. Impact of a switch to fingolimod versus staying on glatiramer acetate or beta interferons on patient- and physician-reported outcomes in relapsing multiple sclerosis: post hoc analyses of the EPOC trial. BMC Neurol. 2014;14:220.

54. Fox E, Edwards K, Burch G, et al. Outcomes of switching directly to oral fingolimod from injectable therapies: results of the randomized, open-label, multicenter, Evaluate Patient OutComes (EPOC) study in relapsing multiple sclerosis. Mult Scler Relat Disord. 2014;3:607-19.

55. Ziemssen T, Calabrese P, Penner IK, Apfel R. QualiCOP: realworld effectiveness, tolerability, and quality of life in patients with relapsing-remitting multiple sclerosis treated with glatiramer acetate, treatment-naïve patients, and previously treated patients. J Neurol. 2016;263:784-91.

56. Coretti S, Ruggeri M, McNamee P. The minimum clinically important difference for EQ-5D index: a critical review. Expert Rev Pharmacoecon Outcomes Res. 2014;14:221-33.

57. Miller DM, Weinstock-Guttman B, Bourdette D, You X, Foulds $\mathrm{P}$, Rudick RA. Change in quality of life in patients with relapsing-remitting multiple sclerosis over 2 years in relation to other clinical parameters: results from a trial of intramuscular interferon $\beta$-1a. Mult Scler. 2011;17:734-42.

58. Mokhber N, Azarpazhooh A, Orouji E, et al. Therapeutic effect of Avonex, Rebif and Betaferon on quality of life in multiple sclerosis. Psychiatry Clin Neurosci. 2015;69:649-57.

59. Newsome SD, Guo S, Altincatal A, et al. Impact of peginterferon beta-1a and disease factors on quality of life in multiple sclerosis. Mult Scler Relat Disord. 2015;4:350-7.

60. Phillips GA, Wyrwich KW, Guo S, et al. Responder definition of the Multiple Sclerosis Impact Scale physical impact subscale for patients with physical worsening. Mult Scler. 2014;20:1753-60.

61. Freeman JA, Thompson AJ, Fitzpatrick R, et al. Interferon-beta1b in the treatment of secondary progressive MS: impact on quality of life. Neurology. 2001;57:1870-5.

62. Cohen JA, Cutter GR, Fischer JS, et al. Benefit of interferon beta-1a on MSFC progression in secondary progressive MS. Neurology. 2002;59:679-87.

63. Arnoldus JH, Killestein J, Pfennings LE, Jelles B, Uitdehaag $\mathrm{BM}$, Polman $\mathrm{CH}$. Quality of life during the first 6 months of interferon-beta treatment in patients with MS. Mult Scler. 2000;6:338-42.

64. Lily O, McFadden E, Hensor E. Disease-specific quality of life in multiple sclerosis: the effect of disease modifying treatment. Mult Scler. 2006;12:808-13.

65. Vermersch P, De Seze J, Delisse B, Lemaire S, Stojkovic T. Quality of life in multiple sclerosis: influence of interferon-beta1a $\left(\right.$ Avonex ${ }^{\circledR}$ ) treatment. Mult Scler. 2002;8:377-81.

66. Zivadinov R, Zorzon M, Tommasi MA, et al. A longitudinal study of quality of life and side effects in patients with multiple sclerosis treated with interferon beta-1a. J Neurol Sci. 2003;216:113-8.

67. Jongen PJ, Sindic C, Carton H, Zwanikken C, Lemmens W, Borm G. Improvement of health-related quality of life in relapsing remitting multiple sclerosis patients after 2 years of treatment with intramuscular interferon-beta-1a. J Neurol. 2010;257:584-9.

68. Patti F, Amato MP, Trojano M, et al. Quality of life, depression and fatigue in mildly disabled patients with relapsing-remitting multiple sclerosis receiving subcutaneous interferon beta-1a: 3 -year results from the COGIMUS (COGnitive Impairment in MUltiple Sclerosis) study. Mult Scler. 2011;17:991-1001.

69. Patti F, Pappalardo A, Montanari E, Pesci I, Barletta V, Pozzilli C. Interferon-beta-1a treatment has a positive effect on quality of life of relapsing-remitting multiple sclerosis: results from a longitudinal study. J Neurol Sci. 2014;337:180-5.

70. Moore F, Vickrey B, Fortin K, Lee L. Two multiple sclerosis quality-of-life measures: comparison in a national sample. Can $\mathbf{J}$ Neurol Sci. 2015;42:55-63.

71. Pakdaman H, Amini Harandi A, Gharagozli K, et al. Healthrelated quality of life in patients with relapsing-remitting multiple sclerosis treated with subcutaneous interferon $\beta-1 \mathrm{a}$ in Iran. Int J Neurosci. 2017;127:501-7.

72. Wolinsky JS, Borresen TE, Dietrich DW, et al. GLACIER: an open-label, randomized, multicenter study to assess the safety and tolerability of glatiramer acetate $40 \mathrm{mg}$ three-times weekly versus $20 \mathrm{mg}$ daily in patients with relapsing-remitting multiple sclerosis. Mult Scler Relat Disord. 2015;4:370-6.

73. Jongen PJ, Lehnick D, Sanders E, et al. Health-related quality of life in relapsing remitting multiple sclerosis patients during treatment with glatiramer acetate: a prospective, observational, international, multi-centre study. Health Qual Life Outcomes. 2010;8:133.

74. Jongen PJ, Lehnick D, Koeman J, et al. Fatigue and healthrelated quality of life in relapsing-remitting multiple sclerosis after 2 years glatiramer acetate treatment are predicted by changes at 6 months: an observational multi-center study. J Neurol. 2014;261:1469-76.

75. Ziemssen T, Bajenaru OA, Carrá A, et al. A 2-year observational study of patients with relapsing-remitting multiple sclerosis converting to glatiramer acetate from other diseasemodifying therapies: the COPTIMIZE trial. J Neurol. 2014;261:2101-11.

76. Stephenson JJ, Kern DM, Agarwal SS, et al. Impact of natalizumab on patient-reported outcomes in multiple sclerosis: a longitudinal study. Health Qual Life Outcomes. 2013;10:155.

77. Montalban X, Comi G, O’Connor P, et al. Oral fingolimod (FTY720) in relapsing multiple sclerosis: impact on health-related quality of life in a phase II study. Mult Scler. 2011;17:1341-50.

78. Gold SM, Schulz H, Stein H, et al. Responsiveness of patientbased and external rating scales in multiple sclerosis: head-tohead comparison in three clinical settings. J Neurol Sci. 2010;290:102-6.

79. Schäffler N, Schönberg P, Stephan J, Stellmann JP, Gold SM, Heesen C. Comparison of patient-reported outcome measures in multiple sclerosis. Acta Neurol Scand. 2013;128:114-21.

80. Calabresi PA, Radue EW, Goodin D, et al. Safety and efficacy of fingolimod in patients with relapsing-remitting multiple sclerosis (FREEDOMS II): a double-blind, randomised, placebo-controlled, phase 3 trial. Lancet Neurol. 2014;13:545-56.

81. Hersh CM, Hara-Cleaver C, Rudick RA, Cohen JA, Bermel RA, Ontaneda D. Experience with fingolimod in clinical practice. Int J Neurosci. 2015;125:678-85.

82. Kappos L, Gold R, Arnold DL, Bar-Or A, Giovannoni G, Selmaj $\mathrm{K}$, et al. Quality of life outcomes with BG-12 (dimethyl fumarate) in patients with relapsing-remitting multiple sclerosis: the DEFINE study. Mult Scler. 2014;20:243-52.

83. Kita M, Fox RJ, Phillips JT, et al. Effects of BG-12 (dimethyl fumarate) on health-related quality of life in patients with relapsing-remitting multiple sclerosis: findings from the $\mathrm{CON}$ FIRM study. Mult Scler. 2014;20:253-7.

84. Kita M, Fox RJ, Gold R, et al. Effects of delayed-release dimethyl fumarate (DMF) on health-related quality of life in patients with relapsing-remitting multiple sclerosis: an integrated analysis of the phase 3 DEFINE and CONFIRM studies. Clin Ther. 2014;36:1958-71.

85. Lee A, Pike J, Edwards MR, Petrillo J, Waller J, Jones E. Quantifying the benefits of dimethyl fumarate over $\beta$ interferon and glatiramer acetate therapies on work productivity outcomes 
in MS patients. Neurol Ther. 2017. doi:10.1007/s40120-0160061-5.

86. Confavreux C, Li DK, Freedman MS, et al. Long-term followup of a phase 2 study of oral teriflunomide in relapsing multiple sclerosis: safety and efficacy results up to 8.5 years. Mult Scler. 2012;18:1278-89.

87. Arroyo González R, Kita M, Crayton H, et al. Alemtuzumab improves quality-of-life outcomes compared with subcutaneous interferon beta-1a in patients with active relapsing-remitting multiple sclerosis. Mult Scler. 2016. doi:10.1177/ 1352458516677589.

88. Gold R, Giovannoni G, Selmaj K, et al. Daclizumab high-yield process in relapsing-remitting multiple sclerosis (SELECT): a randomised, double-blind, placebo-controlled trial. Lancet. 2013;381:2167-75.

89. Phillips G, Guo S, Bender R, Havrdová E, Proskorovsky I, Vollmer T. Assessing the impact of multiple sclerosis disease activity and daclizumab HYP treatment on patient-reported outcomes: results from the SELECT trial. Mult Scler Relat Disord. 2016;6:66-72.

90. Liu Y, Vollmer T, Havrdova E, et al. Impact of daclizumab versus interferon beta-1a on patient-reported outcomes in relapsing-remitting multiple sclerosis. Mult Scler Relat Disord. 2017;11:18-24.

91. Hauser SL, Bar-Or A, Comi G, et al. Ocrelizumab versus interferon beta-1a in relapsing multiple sclerosis. N Engl J Med. 2017;376:221-34.

92. Montalban X, Hauser SL, Kappos L, et al. Ocrelizumab versus placebo in primary progressive multiple sclerosis. $\mathrm{N}$ Engl $\mathrm{J}$ Med. 2017;376:209-20.

93. Cocks K, King MT, Velikova G, Fayers PM, Brown JM. Quality, interpretation and presentation of EORTC QLQ-C30 data in randomised controlled trials. Eur $\mathrm{J}$ Cancer. 2008:44:1793-8.

94. King MT. A point of minimal important difference (MID): a critique of terminology and methods. Expert Rev Pharmacoecon Outcomes Res. 2011;11:171-84.

95. Norman GR, Sloan JA, Wyrwich KW. Interpretation of changes in health-related quality of life: the remarkable universality of half a standard deviation. Med Care. 2003;41:582-92.

96. Jongen PJ, Lemmens WA, Hoogervorst EL, Donders R. Glatiramer acetate treatment persistence-but not adherence-in multiple sclerosis patients is predicted by health-related quality of life and self-efficacy: a prospective web-based patient-centred study (CAIR study). Health Qual Life Outcomes. 2017;15:50.
97. Schwartz CE, Andresen EM, Nosek MA, Krahn GL. Response shift theory: important implications for measuring quality of life in people with disability. Arch Phys Med Rehabil. 2007;88:529-36.

98. Lix LM, Chan EK, Sawatzky R, et al. Response shift and disease activity in inflammatory bowel disease. Qual Life Res. 2016;25:1751-60.

99. Chua AS, Glanz BI, Guarino AJ, et al. Patient-reported outcomes in multiple sclerosis: relationships among existing scales and the development of a brief measure. Mult Scler Relat Disord. 2015;4:598-606.

100. Rosato R, Testa S, Bertolotto A, et al. Development of a short version of MSQOL-54 using factor analysis and item response theory. PLoS One. 2016;11(4):e0153466.

101. Michel P, Baumstarck K, Ghattas B, et al. A multidimensional computerized adaptive short-form quality of life questionnaire developed and validated for multiple sclerosis: the MusiQoLMCAT. Medicine (Baltimore). 2016;95:e3068.

102. Jongen PJ, Sanders E, Zwanikken C, et al. Adherence to monthly online self-assessments for short-term monitoring: a 1 -year study in relapsing-remitting multiple sclerosis patients after start of disease modifying treatment. Patient Prefer Adherence. 2013;7:293-300.

103. Jongen PJ, Sinnige LG, van Geel BM, et al. The interactive webbased program MSmonitor for self-management and multidisciplinary care in multiple sclerosis: concept, content, and pilot results. Patient Prefer Adherence. 2015;9:1741-50.

104. Jongen PJ, Sinnige LG, van Geel BM, et al. The interactive webbased program MSmonitor for self-management and multidisciplinary care in multiple sclerosis: utilization and valuation by patients. Patient Prefer Adherence. 2016;10:243-50.

105. Fox RJ, Bacon TE, Chamot E, et al. Prevalence of multiple sclerosis symptoms across lifespan: data from the NARCOMS Registry. Neurodegener Dis Manag. 2015;5(6 Suppl):3-10.

106. Hillert J, Stawiarz L. The Swedish MS registry—clinical support tool and scientific resource. Acta Neurol Scand. 2015;132:11-9.

107. Janzen W, Turpin KV, Warren SA, Marrie RA, Warren KG. Change in the health-related quality of life of multiple sclerosis patients over 5 years. Int J MS Care. 2013;15:46-53.

108. Jongen PJ, Heerings M, Lemmens WA, Donders R, van der Zande A, van Noort E, Kool A. A prospective web-based patient-centred interactive study of long-term disabilities, disabilities perception and health-related quality of life in patients with multiple sclerosis in The Netherlands: the Dutch Multiple Sclerosis Study protocol. BMC Neurol. 2015;15:128. 